\title{
CRIANÇA E ANIMAIS SILVESTRES- A FALA DE CRIANÇAS DE 4 e 5 ANOS SOBRE A EXPOSIÇÃO "BICHO QUEM TE VIU QUEM TE VÊ!”
}

\author{
Sandra Fagionato-Ruffino ${ }^{1}$ \\ Keila Erika Ikuno ${ }^{2}$ \\ Paulo Henrique Peira Ruffino ${ }^{3}$
}

\section{RESUMO}

Este trabalho procurou interpretar a compreensão de crianças de 4 e 5 anos sobre a temática de animais silvestres e conflitos regionais após a visitação à Exposição Itinerante "Bicho, quem te viu, quem te vê"! onde observaram e interagiram por meio de imagens, sons e materiais biológicos com elementos da fauna silvestre regional. A metodologia de estudo baseou-se em conversas com 4 turmas de crianças de uma Escola Municipal de Educação Infantil mediadas por fotografias da exposição. A análise do processo da visita e posterior conversa demonstrou que as crianças apresentaram significativo interesse e boa memória em relação à Exposição, em especial aos animais taxidermizados, com ampliação do vocabulário sobre a fauna silvestre.

PALAVRAS-CHAVE: Educação Infantil, Animais Silvestres, Educação Ambiental.

\section{CHILD AND WILD ANIMALS - CHILDREN TALKING 4 AND 5 YEARS ON THE EXHIBITION " ANIMAL WHO SAW YOU WHO YOU SEE! "}

\begin{abstract}
This study sought to interpret the understanding of children aged 4 and 5 years on the subject of wild animals and regional conflicts after visiting the traveling exhibition "Animal, who saw it, who sees it!" where they observed and interacted through images, sounds and biological materials with elements of regional wildlife. The study methodology was based on conversations with 4 groups of children from a Municipal School of Early Childhood Education mediated by exposure photographs. The analysis of the business process and subsequent conversation showed that the children demonstrate significant interest and good memory in relation to the exhibition, especially the taxidermized animals with vocabulary expansion on wildlife.
\end{abstract}

KEYWORDS: Childhood Education, Wild Animals, Environmental Education

\footnotetext{
1 Ecóloga, Doutora em Educação pela Universidade Federal de São Carlos, professora de educação infantil da rede municipal de São Carlos - SP. E-mail: fagionato.sandra@gmail.com

${ }^{2}$ Pedagoga, Especialista em Psicopedagogia, professora assistente em educação infantil e ensino fundamental da rede municipal de Itirapina - SP. E-mail: keilaerika@gmail.com

${ }^{3}$ Ecólogo, Pesquisador Científico - Manejo de Áreas Silvestres - Educação Ambiental do Instituto Florestal, Secretaria de Meio Ambiente do Estado de São Paulo. E-mail: phruffino@if.sp.gov.br
} 


\section{NIÑOS Y ANIMALES SIL VESTRES- QUE HABLAN NIÑOS DE 4 Y 5 AÑOS EN LA EXPOSICIÓN " BICHO QUE TE VIO QUE TE VE !"}

\section{RESUMEN}

Este estudio trata de interpretar la comprensión de niños de 4 y 5 años en el tema de los animales salvajes y los conflictos regionales después de visitar la exposición itinerante "Bicho, que te vio, que te ve!" donde observaron e interactuaron a través de imágenes, sonidos y materiales biológicos con elementos de la fauna regional. La metodología del estudio se basó en conversaciones con 4 grupos de niños de una Escuela Municipal de Educación Infantil mediadas por las fotografías de la exposición. El análisis de los procesos de negocio y la conversación posterior mostró que los niños mostraron gran interés y buena memoria en relación con la exposición, especialmente los animales taxidermizados con la expansión del vocabulario en la vida silvestre.

PALAVRAS CLAVE: Educación Infantil, Animales Silvestres, Educación Ambiental

\section{INTRODUÇÃO}

O Brasil é considerado, atualmente, o país que concentra a maior biodiversidade do planeta (MITTERMEIR et al, 1997). Uma das expressões dessa grande biodiversidade é a sua rica e exuberante fauna, constituída de mais de 100 mil espécies, entre mamíferos, aves, anfíbios, peixes, répteis, insetos e outros invertebrados (MACHADO et al, 2005). Mais que nunca, precisamos conhecer a biodiversidade existente, identificar os principais fatores que a ameaçam e estabelecer prioridades de ação.

O desenvolvimento de um processo pedagógico eficiente é fruto de pesquisa, aplicação, análise e, acima de tudo, de uma sintonia entre educandos e educador. Este processo apurado e bilateral requer que as partes estejam sensíveis aos conceitos e práticas objetivados e, neste sentido, o desenvolvimento de processos pedagógicos quem envolvam temas atrativos tendem a alcançar resultados mais eficientes. Com a temática da fauna, isto é, o conjunto de animais, o processo pedagógico junto a crianças parece ser catalisado no que tange a atenção e interesse. Representantes de seres vivos da mega fauna sempre estão no imaginário das crianças, basta perguntar sobre algum bicho que conheçam para que logo se tenha respostas como "tubarão", " leão”, "urso", "girafa”, etc.

Considerando-se que a efetividade de um processo de educação ambiental deva desenvolver junto a educadores e educandos momentos de reflexão sobre as questões cotidianas próximas aos mesmos, definir estratégias pedagógicas baseadas na identificação, interpretação e interação com representantes da fauna 
devem necessariamente focar as condições e espécies locais, isto é, a fauna silvestre. No entanto, o que se identifica em geral são ações, estruturas e estratégias educativas restritas ao uso de elementos e animais característicos de outras regiões do planeta, como África, Europa, exatamente os que aparecem em rápida argüição de crianças sobre quais bichos conhecem!

O pensar e planejar novas propostas pedagógicas que contemplem as questões de fauna silvestre, educação ambiental e crianças devem, portanto, considerar as diferenças ambientais de cada região escolhida e não homogeneizar padrões globais.

Entre os anos de 2012 e 2014, na região central paulista, o Centro de Divulgação Científica e Cultural (CDCC) da Universidade de São Paulo em parceria com o Instituto Florestal e Fundação Florestal / Secretaria do Meio Ambiente do Estado de São Paulo e o Laboratório de Educação Ambiental da Universidade Federal de São Carlos, estudaram, elaboraram e implantaram a Exposição Itinerante Bicho, quem te viu, quem te vê! de forma a contribuir para o desenvolvimento de processos educativos sobre a temática da fauna regional e os atuais conflitos com as sociedades limítrofes (RUFFINO et al, 2015). Idealizada para ser realizada de forma itinerante em diferentes municípios, a exposição auxilia o processo de interpretação da vida dos animais típicos da região central do estado de São Paulo nos seus respectivos ambientes (Cerrado, Mata Mesófila Semidecidual e Mata Ciliar)

$\mathrm{Na}$ passagem da Exposição pelo município de Itirapina-SP, foram realizados 1550 atendimentos a estudantes da rede municipal e estadual de ensino público sendo, nesta oportunidade, registrados por meio de relatório de monitoramento. Percebeu-se que as crianças da educação infantil (de 4 e 5 anos) apresentaram significativo interesse sobre a exposição e elementos expostos, em especial os animais taxidermizados.

Com este resultado não esperado da exposição junto ao público da Educação Infantil, a ideia mencionada anteriormente de que as crianças têm pouco acesso a materiais e ações pedagógicas relacionadas aos animais da fauna brasileira e, por fim a reconhecida dificuldade de professores acessarem materiais desta natureza (SCALFI e BARATA, 2014), acreditamos que a Exposição Itinerante Bicho, quem te viu, quem te vê! possa ser um recurso viável para a educação infantil se avaliada com critério para esta faixa de público. Neste sentido questionamos: que 
ideias e conhecimentos sobre a fauna silvestre brasileira as crianças constroem a partir da exposição? Quais são os elementos ou aspectos mais significativos para as crianças? Que ideias sobre a relação ser humano e fauna silvestre as crianças elaboram?

\section{OBJETIVO}

Identificar junto às crianças de educação infantil que frequentaram a Exposição Itinerante Bicho, quem te viu, quem te vê!, quais os aspectos mais significativos;

Identificar ideias elaboradas a partir da vivência sobre a fauna nativa e sua relação com o ser humano;

Analisar o potencial da exposição para o público da educação infantil.

\section{PERCURSO METODOLÓGICO}

\section{A Exposição Itinerante Bicho quem te viu, quem te vê!}

A utilização da ferramenta pedagógica da Exposição Itinerante Bicho, quem te viu, quem te vê! na presente pesquisa se deu pela inovação e aprofundamento de questões locais/regionais na interpretação das questões da fauna silvestre do interior do estado de São Paulo. Segundo CDCC (2015) a Exposição foi idealizada para sensibilizar, propiciar reflexões e trazer argumentos para que cidadãos, instituições e organizações sociais ajam em prol da conservação desta importante biodiversidade paulista. A Exposição está organizada em cinco Estações temáticas que se ligam por meio de uma pista com sinalização horizontal e vertical simulando uma rodovia (Figuras 1 e 2), painéis e outros elementos da fauna (animais taxidermizados, ossos, pegadas).

Figuras 1 e 2: Estações com pista interligando-as
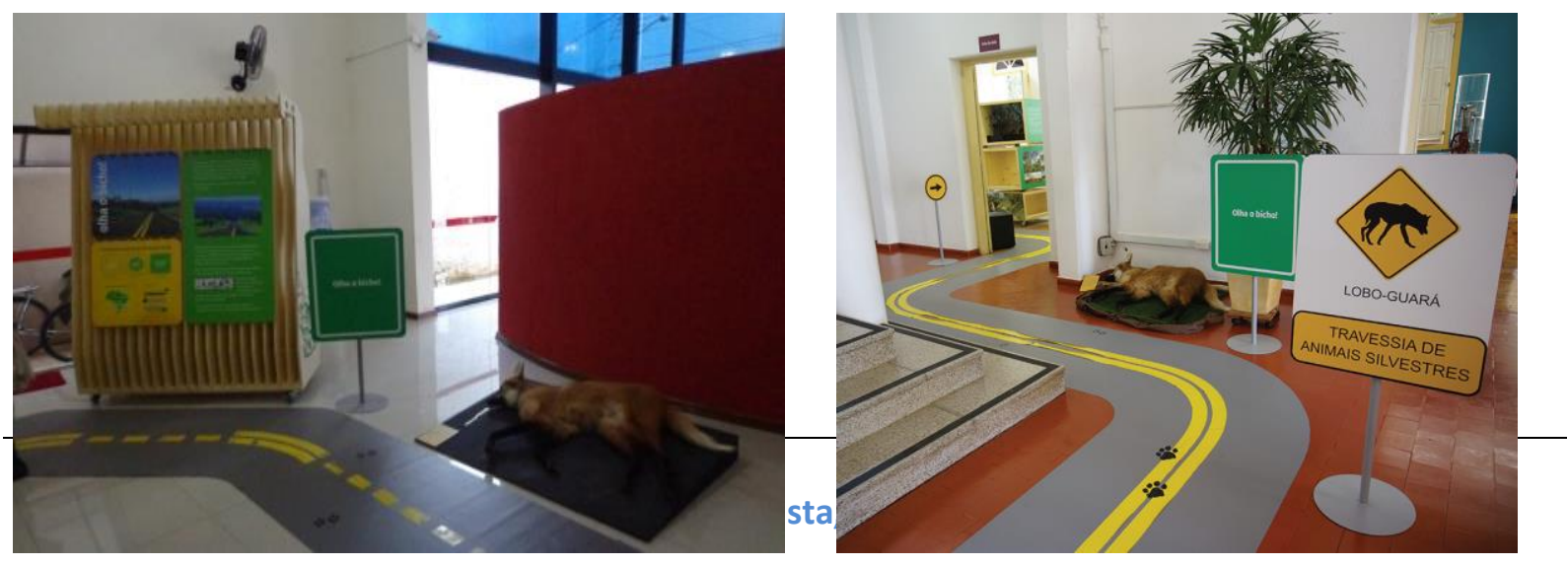
Com base nos objetivos elencados por Ruffino et al (2015) as Estações foram percorridas com as crianças seguindo - se a seqüência:

1. Abertura - Apresentar a existência de uma biodiversidade e ambientar, motivar, instigar o visitante a percorrer a exposição. Esta estação conta com imagens e sons de animais silvestres e, neste momento as crianças participantes foram convidadas a observarem as imagens e citarem quais animais reconheciam pela fisionomia. Em seguida foi solicitado que fechassem os olhos e que ouvissem os sons da natureza local (primatas, aves, água, felinos, etc); ao final dos sons da natureza há um som de freada de automóvel com seguido por um gemido simulando um atropelamento.

2. Olha o Bicho - Sensibilizar os visitantes para o problema do atropelamento; apresentar os motivos do atropelamento. A Estação conta com um indivíduo adulto de Lobo-guará taxidermizado em posição de atropelado ao lado da pista, com uma simulação de sangue escorrendo da boca (tinta). Neste momento as crianças passavam pelo lobo e paravam para tocar e perceber o que havia ocorrido (atropelamento).

3. Por onde os Bichos estão andando? Apresentar a evolução da paisagem no Estado de São Paulo (demonstração da fragmentação das áreas naturais); apresentar as condições dos animais frente ao problema da fragmentação. A estação é composta de 2 animais taxidermizados (Tamanduá-mirim e Jaguatirica) que são manuseados para explicar como eles se deslocam quando há passagens de fauna junto as rodovias (Figura 3).

Figura 3: Simulação de travessia sem passagem de fauna

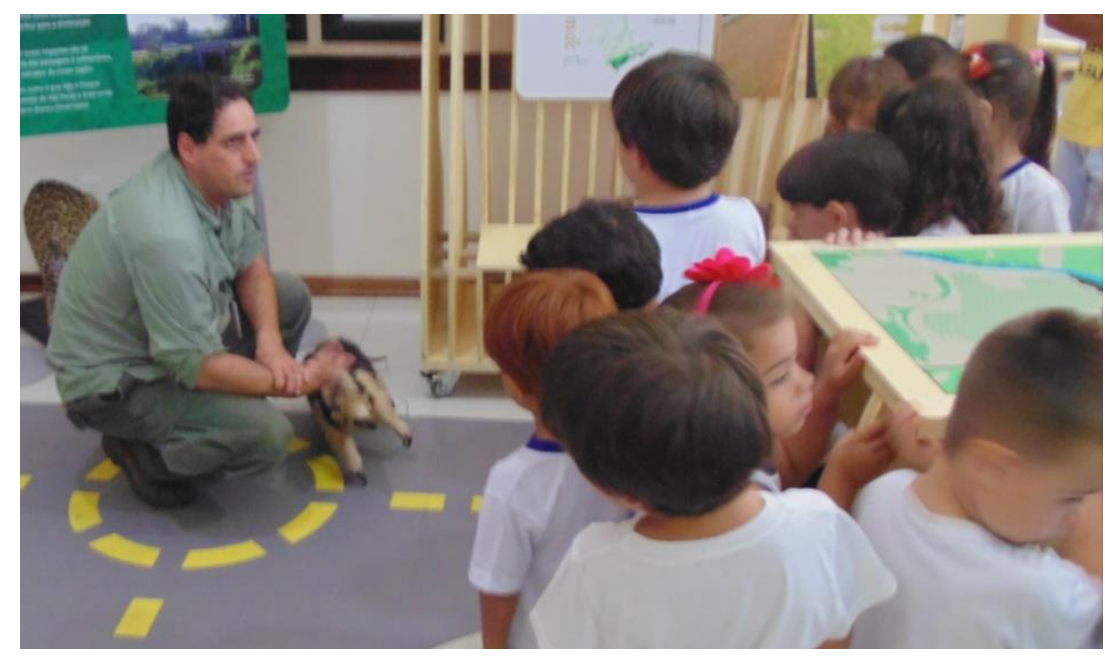


4. Onde os Bichos vivem - Apresentar as áreas naturais ou biomas que ocorrem na região, alguns animais característicos desses ambientes e vestígios como crânio, pegadas e ovos. A estação apresenta imagens e elementos dos ambientes que compõem as paisagens da região central paulista: Cerrado, Mata Ciliar e Mata Mesófila Semidecídua. Neste espaço as crianças observaram animais (taxidermizados e imagens) e as características de cada ambiente.

As estações seguintes Convivendo com os Bichos! e E nós com isto? não foram desenvolvidas com a crianças devido a temática ser considerada mais difícil de interpretar no tempo útil disponível. A visita foi encerrada no painel composto por uma televisão e reportagens escritas (ilustrações de jornais e revistas) que apresentam notícias de animais encontrados em ambientes urbanos de cidades próximas. Para as crianças foi escolhido o vídeo-notícia de aparecimento de Onçaparda no município de Itirapina no ano de 2011. A reportagem virou notícia nacional e as imagens locais foram reconhecidas por várias crianças.

A visita com cada uma das turmas da educação infantil durou pouco mais de 30 minutos.

\section{Coleta de Dados}

Os estudos da infância alertam para as diferenças de poder entre crianças e adultos e a dificuldade dos adultos darem voz e compreenderem as crianças. Neste sentido vários autores (SARMENTO e PINTO, 1997; DEMARTINI, 2009; FARIA, 2009 e 2011) destacam a necessidade de se desenhar estratégias metodológicas que facilitem a interlocução entre adultos e crianças; trata-se de ouvir as crianças considerando-as "informantes qualificados, sobre a constituição da infância nas diferentes instâncias sociais" (FARIA, 2011, p. vii).

Considerando que neste estudo é interesse ouvir as crianças sobre o que se lembram da exposição, bem como sobre as ideias que construíram ou que estão construindo a partir do que viram e ouviram e tomando como partida nossa dificuldade de estabelecer uma comunicação com estas crianças, foi delineada uma metodologia de coleta de dados focada em conversas com grupos de crianças, mediadas por fotografias da exposição. 
Esta metodologia foi escolhida por acreditarmos que quando em grupo, as crianças se ajudam, as memórias de uma vão se constituindo na memória do outro e coletivamente construindo um texto ou narrativa. A fotografia para nós tem a função de estabelecer uma conversação com as crianças participantes do estudo como sugere Luttrell (2010), resgatar suas lembranças e revisitar os espaços visitados suscitando junto às crianças a necessidade de falarem sobre o que viram, ouviram, sentiram, expondo o que pensam agora. Martins Filho (2010) com base nos autores analisados coloca a fotografia como a possibilidade de ver e rever a cena, os personagens e o contexto, o que

aguça a memória, a imaginação, a criação e a reconstituição da própria história vivida, pelas imagens e nas imagens. (...) A fotografia mostra sempre o passado lido aos olhos do presente, embora já não seja o mesmo passado, mas sua leitura ressignificada. (p. 11)

Para Luttrell (2010, p. 231), a narrativa é um discurso constituído por muitas vozes e os significados produzidos, compartilhados, contestados e atribuídos de acordo com cada experiência. Os pontos de vistas das crianças sobre um assunto nem sempre são os mesmos, nem sempre falam com a coerência de uma fala adulta, mas ainda assim tem o valor do diálogo, promovendo espaço para autoria e pertencimento cultural.

Em estudos da infância temos visto alguns trabalhos que se utilizam da autofotografia como forma de ampliar a participação das crianças no estudo (LUTTRELL, 2010; SILVEIRA, 2005). Em nosso caso, construímos uma metodologia utilizando-se da foto como modelo (NEIVA-SILVA e KOLLER, 2002) ${ }^{4}$. Segundo as autoras, o uso da foto como modelo tem como objetivo apresentar aos participantes do estudo fotografias cujo tema relaciona-se ao objeto de estudo e a partir daí analisar suas percepções, falas ou reações em relação a elas.

Foram selecionadas fotografias da exposição feitas pela equipe, destacando cada uma das estações e seus elementos constituintes bem como a participação de

\footnotetext{
4 Em estudo sobre o uso da fotografia na pesquisa psicológica as autoras estabelecem quatro funções para seu uso: registro, modelo, autofotográfica e feedback. A primeira trata da foto como documentação; a terceira da análise de conteúdos de fotos feitas pelo próprio participante da pesquisa e por fim como feedback a fim de testar a sua influência sobre algum aspecto avaliado anteriormente.
} 
cada sala de aula na visita. Estas imagens foram utilizadas em conversas realizadas com todas as crianças de uma Escola Municipal de Educação Infantil (EMEI) que haviam participado da visita à exposição 4 semanas antes. A escolha da unidade escolar se deu em função do pronto consentimento da direção escolar e a organização viabilizada por uma das pesquisadoras envolvidas que é docente assistente.

Como o intuito era conhecer as percepções e construções do grupo e não de cada criança, estas foram organizadas pelas turmas às quais pertencem (classes), em semi-círculo na sala de informática da própria EMEI, espaço em que estão habituadas a freqüentar com respectivos docentes. Dois dos pesquisadores também já eram conhecidos das crianças, seja da própria escola, seja da monitoria da exposição.

A conversa foi organizada em três momentos:

1. Contextualização: constitui-se na introdução do assunto e teve como referência inicial a pergunta sobre conhecerem um dos pesquisadores, de onde o conheciam e o que viram no local. A intenção era iniciar uma conversa geral para identificar o se lembravam e que aspectos teriam chamado mais a atenção a ponto de quererem falar à respeito;

2. Observação das imagens: a partir da conversa inicial, as imagens da exposição foram apresentadas (via projeção em tela) às crianças, na ordem em que os espaços e elementos apareciam na exposição com o intuito de trazer à tona suas idéias e vozes. Em algum caso quando não falavam nada, questionava-se: se lembram disso? Sabem o nome? O que aconteceu aí?

3. Fechamento: Após observação de todas as imagens, as crianças, uma a uma respondiam à pergunta: $O$ que mais gostaram na exposição?

Para o estudo foram utilizadas as conversas realizadas com as 4 turmas do período da manhã, totalizando 66 crianças de idade entre 4 e 5 anos sendo uma turma de pré I e três de pré II.

Toda a conversa realizada foi gravada em vídeo e posteriormente transcrita. Para análise foram consideradas as falas das crianças, bem como gestos e interações estabelecidas entre elas e os pesquisadores. 


\section{RESULTADOS}

Durante a conversa inicial percebemos que alguns elementos são recorrentes às quatro turmas como, por exemplo, a lembrança de exemplares de lobo- guará e da onça parda. Duas turmas foram além da fala do nome do animal e explicaram a situação destacada na exposição: atropelamento do lobo; em uma delas, a criança explica o motivo do lobo atravessar a pista e o funcionamento da passagem de fauna para evitar o atropelamento. Houve ainda uma criança que afirmou ter pensado que o lobo estivesse dormindo.

Ao falarem da onça parda ora a chamavam de tigre, ora de onça magra ou onça parda; e em uma das turmas foi destacado o episódio de uma reportagem em que subia na árvore gerando uma discussão entre as crianças, pois uma delas inicia falando que era o lobo e outra complementa corrigindo e dizendo que era a onça. Estas e outras duas crianças recriam a narrativa que assistiram na exposição complementando com explicações simples: ela sobre na árvore porque sabe; ela ficou presa; "ela usa as garras" Outras duas crianças ajudam na explicação reconstruindo dizendo que "ela ficou presa" e "ela usa garra" (fala fazendo gesto com as mãos e mostrando os dedos em forma de garras).

Outros animais (tucano onça pintada, ouriço e tamanduá) aparecem no início da conversa em duas turmas.

Uma turma não explorou nenhum destes elementos no início da conversa, mas as crianças demonstram lembrarem-se da exposição ao relacionarem-na com "o lugar dos bichinhos" e "pista e rua". À medida que as imagens foram sendo apresentadas as crianças estas iam falando o que viam ou que lembravam: nomes dos animais, objetos, sons. Demonstraram boa memória lembrando-se de diversos animais e inclusive de coisas que aconteceram ou foram faladas na exposição, como por exemplo, que deveriam andar na pista e que havia acendido a luz.

Apenas em uma das turmas falou-se sobre o som de freada no início da exposição e explicaram que era o barulho que matava o lobo. As demais turmas trataram deste assunto apenas durante a observação da imagem que mostrava este painel, sendo que uma turma não fez menção alguma sobre o som da freada e uma criança o relacionou ao rugido de uma onça. 
A placa de travessia de animais foi explicada em todas as turmas e a ela sempre associada a ideia de que os carros devem parar para esperar o lobo passar e que no caso do lobo morto da exposição, o carro não parou e atropelou-o:

"a placa avisa que tem lobo andando"

Uma criança disse que falou pra mãe que é preciso esperar o lobo passar. Todas as turmas explicaram a passagem de fauna, mas demonstraram ter compreendido melhor a passagem em túnel, por baixo da pista. Uma criança associou-a a casa do lobo.

Apenas uma criança lembrou-se de um quebra-cabeça que retratava a ocupação humana e destacou que sobrou pouco espaço para os animais viverem. Os painéis que retratavam os ambientes de vida dos animais não demonstraram muito interesse, mas em geral as crianças explicam ser a floresta, nem sempre relacionando ao ambiente de vida dos animais. Estas fotografias parecem ter sido lidas pelas crianças mais do ponto de vista da interpretação, como algo novo, que decodificam no momento em que observam a imagem, do que como uma lembrança de algo que viram na exposição.

Quanto ao painel que retratava fogo no cerrado, o que parece ter chamado mais atenção foi o acender da luz (mecanismo usado no painel), sendo que em duas turmas explicaram que os animais morrem e fogem quando a mata pega fogo.

Quanto aos nomes dos animais, as crianças confundem tamanduá com tatu várias vezes, mesmo após falarmos a denominação correta; a jaguatirica, onça pintada e a onça parda também causam confusão de denominação. As pacas são denominadas de ratinho, capivara e sempre explicando ser a mamãe e o filhinho. Em três turmas as crianças associam os crânios a ossos de dinossauros, sendo que em uma delas as pegadas no chão da exposição são do coelhinho.

Em duas turmas surgem questionamentos sobre porque os bichos estavam mortos; por que a onça estava pendurada e como levaram o lobo guará se estava sangrando. Algumas crianças perceberam "o sangue" apenas durante a conversa graças à fala dos colegas e chegaram a questionar se era sangue de verdade.

Uma criança fala que o lobo estava sujo de graxa nas pernas, referindo-se à pelagem mais escura nas pernas.

Analisando as respostas das crianças à pergunta sobre o que mais gostaram na visita, podemos perceber (quadro 1) que o lobo foi o elemento que mais se 
destacou, seguido pela onça, o que é visível também durante toda a conversa com as crianças.

Quadro 1: Frequência das preferências das criança
\begin{tabular}{|l|c|}
\hline Elemento & Frequência \\
\hline Lobo & 19 \\
\hline Cobra & 9 \\
\hline tucano & 7 \\
\hline aranha & 5 \\
\hline onça pintada & 4 \\
\hline onça parda & 4 \\
\hline tamanduá & 3 \\
\hline Coruja & 3 \\
\hline onça & 3 \\
\hline lobo mau & 2 \\
\hline jaguatirica & 1 \\
\hline Paca & 1 \\
\hline Gato & 1 \\
\hline Leão & 1 \\
\hline porco espinho & 1 \\
\hline pintinho & 1 \\
\hline macaquinho & 1 \\
\hline onça magra & 1 \\
\hline não respondeu & 1 \\
\hline
\end{tabular}

Percebemos no vocabulário das crianças que algumas delas usam a denominação lobo-guará, outros lobo e poucos ainda falam em lobo mau; durante as conversas ao falarem do lobo algumas fazem gestos abraçando o corpo, imitando o amedrontamento, o que pode indicar certa analogia com os perigos da florestas e associação com o lobo mau, ainda que usem a denominação lobo-guará.

Ainda com relação ao vocabulário, ao citarem a onça como o elemento que mais gostaram identificamos 4 categorias de onça: onça pintada, onça parda, onça e onça magra ${ }^{5}$, sendo esta última referente à onça parda taxidermizada, cuja fisionomia ficou bastante alongada.

Por outro lado, vemos ainda entre as respostas, elementos que não possuem uma relação direta com a exposição, nem mesmo com a conversa realizada: leão, pintinho e gato, mas que estão dentro do grupo "animais", assunto

\footnotetext{
${ }^{5}$ Em outros momentos as crianças também chamam as onças de leão e tigre e chamando a jaguatirica de onça.
} 
em pauta. Trata-se de respostas de crianças que pouco se envolveram na conversa, mas que respondem seguindo um raciocínio que mantém alguma relação com o assunto.

Percebemos em diversos momentos que a construção do repertório pelas crianças se dá por meio daquilo que viram/ouviram na exposição, mas também permeado por ideias do universo simbólico construído em outros ambientes, como é o caso da figura do dinossauro que aparece logo no início da conversa em uma das turmas quando ao falarem do ovo grande um grupo de crianças discute de quem era o ovo: de passarinho, de galinha, de cobra ou de dinossauro, e também durante a observação das fotos da exposição ao verem os crânios. Ainda do universo da criança aparecem ao final da conversa o leão e o lobo mau como exemplo do que mais gostaram, além do gato.

Dentre os animais citados a maior freqüência diz respeito aos animais taxidermizados (lobo, tucano, onça parda, tamanduá, jaguatirica, paca, porco espinho e macaquinho) o que sugere que estes elementos exercem um papel interessante na exposição para este público. Em vários momentos percebeu-se a dúvida entre as crianças se estavam mortos, se eram de verdade, como foram levados ali...

\section{CONCLUSÕES}

Por meio das conversas realizadas e análise das narrativas podemos dizer que as crianças demonstraram significativo interesse e boa memória em relação à Exposição Itinerante Bicho: Quem te viu quem te vê! e que esta contribuiu para a construção de ideias e conhecimentos sobre a fauna silvestre brasileira.

O contato com os animais, mesmo que taxidermizados foi importante, pois as crianças puderam tocar e sentir a pelagem e a textura de um animal verdadeiro, o que remeteu ao animal vivo, em alguns casos causando certa dúvida sobre sua condição (vivo, morto, de verdade, de mentira).

Um dos aspectos mais significativos e marcantes que ficou na memória das crianças parece ter sido a imagem do lobo-guará no chão; lembravam que ele havia sido atropelado e que havia ali uma placa sinalizando a travessia de animais. Apesar de explicarem sobre a passagem de fauna, a principal maneira de se evitar 0 
atropelamento dos animais (mais especificamente do lobo) na concepção das crianças ficou por parte do motorista que deveria ir devagar, prestar atenção e frear.

Outra fala recorrente entre as crianças foi sobre a onça parda ou onça magra, como algumas se referiam.

Podemos dizer que para as crianças a proximidade com animais silvestres, ainda que por meio de imagens, é recente e não se cristalizou sequer o seu vocabulário quanto a eles, por isso vemos crianças falando em lobo mau, por exemplo, ou colocando no mesmo grupo animais da fauna local com de outros ambientes ou confundindo as nomenclaturas. Por outro lado uma visita de pouco mais de 30 minutos mostrou-se significativa do ponto de vista da construção de repertório e vocabulário sobre a fauna silvestre sendo que para algumas crianças a visita proporcionou certa compreensão sobre os animais e suas diferenças (de nomenclatura e morfológicas).

A metodologia de pesquisa baseada na apresentação de fotografias às crianças para suscitar suas ideias e falas mostrou-se interessante também do ponto de vista pedagógico, pois vários elementos foram percebidos pelas crianças no momento da observação da foto ou graças às falas dos colegas destacando algum aspecto, alguma observação. A fala dos pesquisadores e professores em alguns momentos também foram no sentido de responder dúvidas como, por exemplo, sobre a pelagem do lobo-guará não estar manchada de graxa, sobre o processo de taxidermização, sobre como os animais foram parar lá e a confirmação da denominação de algum animal como paca, tamanduá, diferença entre onça pintada, onça parda e jaguatirica.

\section{REFERÊNCIAS}

CDCC. Bicho, quem te viu, quem te vê! São Carlos, 2015. Disponível em: <http://www.cdcc.usp.br/novidades/quemteviu.pdf>. Acesso em: 30 mai. 2015.

DEMARTINI, Zeila de Brito Fabri. Infância, pesquisa e relatos orais: um campo de estudos em construção. In: Ana Lúcia Goulart. de; DEMARTINI, Zeila de Brito Fabri; PRADO, Patrícia. Dias. (orgs.) Por uma cultura da infância: metodologias de pesquisa com crianças. Campinas, SP: Autores Associados, 2009. p. 1 -17.

FARIA, Ana Lúcia Goulart de; DEMARTINI, Zeila de Brito Fabri; PRADO, Patrícia Dias, (orgs.). Por uma cultura da Infância: metodologia de pesquisa com crianças. 3.ed. Campinas, SP: Autores Associados, 2009. (Coleção educação contemporânea)

FARIA, Ana Lúcia Goulart de; FINCO, Daniela(orgs.). Sociologia da Infância no Brasil. Campinas, SP: Autores Associados, 2011- (Coleção Polêmica do nosso tempo;102) 
LUTTRELL, Wendy. 'A camera is a big responsibility': a lens for analysing children's visual voices. Visual Studies, v. 25, n. 3, p. 224-237, 2010. Disponível em: <http://www.wendyluttrell.org/files/2012/09/Luttrell-A-Camera-Is-A-Big-Responsibility.pdf.> Acesso em: 02 jun. 2015.

MACHADO, Angelo Barbosa Monteiro; MARTINS, Cassio Soares; DRUMMOND, Glaucia Moreira. Lista da Fauna Brasileira Ameaçada de Extinção: Incluindo as Espécies Quase Ameaçadas e Deficientes em Dados. Belo Horizonte: Fundação Biodiversitas, 2005.160p.

MARTINS FILHO, Altino José. Jeitos de ser criança: balanço de uma década de pesquisas com crianças apresentadas na ANPEd. In: REUNIÃO ANUAL DA ANPEd, 33, 2010, Caxambu. Anais... Caxambu: $\quad$ ANPEd, $2010 . \quad$ p. $1-52 . \quad$ Disponível em: <http://www.anped.org.br/33encontro/app/webroot/files/file/Trabalhos\%20em\%20PDF/GT07-6068-Int.pdf>. Acesso em: 28 mai. 2012.

MITTERMEIER, Russel Alan; ROBLES GIL, Patricio; MITTERMEIER Cristina Goettsch. Megadiversity: Earth's Biologically Wealthiest Nations. CEMEX and Agrupación Sierra Madre. 1997.

NEIVA-SILVA, Lucas; KOLLER, Sílvia Helena. $O$ uso da fotografia na pesquisa em Psicologia. Estudos. de psicologia, v. 7, n. 2, p. 237-250, 2002. Disponível em: $<$ http://www.scielo.br/scielo.php?script=sci_arttext\&pid=S1413-

294X2002000200005\&lng=pt\&nrm=iso>. Acesso em: 25 mai. 2015.

RUFFINO, Paulo Henrique Peira et al. Exposição Itinerante Bicho quem te viu, quem te vê! Instituto Florestal, São Paulo - São Paulo, 2015. 42 p.

SARMENTO, Manuel Jacinto; PINTO, Manuel. As crianças e a infância: definindo conceitos, delimitando o campo. In: PINTO, Manuel; SARMENTO, Manuel Jacinto. As crianças- contextos e identidades. Braga, Portugal: Centro de Estudos da Criança, 1997. p. 7-30.

SCALF. Graziele Ap. de Moraes; BARATA, Germana Fernandes. Fauna brasileira retratada na literatura infantil: instrumento para a divulgação científica. Revista do EDICC, v. 2, p. 63-75, 2014. Encontro de Divulgação de Ciência e Cultura. Disponível em: < http://revistas.iel.unicamp.br/index.php/edicc/article/view/4064/3717>. Acesso em: 02 jun. 2015.

SILVEIRA, Débora de Barros. Falas e imagens: a escola de educação infantil na perspectiva das crianças. 2005. 173p. Tese (Doutorado em Educação) - Centro de educação e Ciências Humanas, Universidade Federal de São Carlos, São Carlos, 2006. 